\title{
Recuo ao cientificismo, paradoxos da transparência e corrupção em educação
}

Almerindo Janela Afonso'

\begin{abstract}
Resumo
Um dos sintomas da razão indolente (SANTOS, 2006) é o recuo ao cientificismo, o qual tem sido, particularmente, acentuado nas políticas, cada vez mais hegemônicas, de avaliação, de prestação de contas e de responsabilização. Por isso, um dos objetivos deste texto é o de colocar em causa este aparente consenso cientificista (ou este consenso supostamente transideológico) e fazer uma breve incursão exploratória ao que aqui se designa de paradoxos da transparência. Considera-se que esses paradoxos traduzem a existência de tensões e contradições relativas a uma dimensão central dos discursos políticos e educacionais contemporâneos. Com isso, o artigo pretende dar continuidade a uma linha de pesquisa que tem procurado sublinhar a relevância da necessidade de complexificar e dar maior rigor teórico-conceptual à accountability em educação. Finalmente, tentando abrir caminho para o desenvolvimento de novas articulações e análises, chama-se a atenção para a corrupção na educação cuja complexidade ainda é insuficientemente conhecida e pesquisada, nomeadamente, nas suas relações com as problemáticas da transparência e da accountability. Admite-se que as práticas de corrupção em educação, em muitas situações, são (paradoxalmente) induzidas pela necessidade de dar resposta à governação baseada nos números, nos rankings e nas (supostas) evidências, anulando completamente as expectativas legitimas em torno da transparência dos processos educacionais e das decisões políticas.
\end{abstract}

\section{Palavras-chave}

Accountability - Transparência - Corrupção em educação. 


\title{
Retreat into scientism, paradoxes of transparency, and corruption in education
}

Almerindo Janela Afonso'

\begin{abstract}
One symptom of "indolent reason" (SANTOS, 2006) is the retreat into scientism, which is especially marked in the increasingly hegemonic policies surrounding assessment, reporting and accountability. As such, one of the aims of this paper is to call into question this apparent consensus on scientism (a supposedly trans-ideological consensus), and briefly explore what we define as the paradoxes of transparency. These paradoxes are found to reveal the existence of tensions and contradictions concerning a central aspect of current political and educational discourse. In doing so, the article seeks to continue a line of study which has aimed to emphasize the significance of the need for a more complex, and theoretically and conceptually rigorous understanding of accountability in education. Finally, in an attempt to pave the way for further discussion and analysis, attention is drawn to corruption in education, the complex nature of which remains insufficiently understood and studied, notably in terms of its relationship with the problems of transparency and accountability. It is acknowledged that practices of corruption within education are, in many situations, (paradoxically) caused by the need to answer to a system of governance based on numbers, league tables, and (supposed) truths, completely nullifying legitimate expectations about the transparency of educational processes and policy decisions.
\end{abstract}

\section{Keywords}

Accountability - Transparency - Corruption in education.

I- Universidade do Minho, Braga, Portugal.

Contact: ajafonso@ie.uminho.pt 


\section{Introdução}

Um dos sintomas da razão indolente (SANTOS, 2006) é o recuo ao cientificismo, o qual é particularmente acentuado nas políticas de avaliação, prestação de contas e responsabilização. Essas políticas, cada vez mais hegemônicas, têm naturalizado e disseminado de tal forma o cientificismo e tecnicismo que já é muito difícil responder à questão se em relação a elas há alguma diferença substantiva quando ocorrem alternâncias de poder em diferentes países e democracias representativas. Por essa razão, um dos objetivos deste artigo é o de pôr em causa esse aparente consenso cientificista (ou esse consenso supostamente transideológico) e fazer uma breve incursão exploratória ao que aqui se designa de paradoxos da transparência. Nesse sendo, considera-se que tais paradoxos traduzem a existência de tensões e contradições relativas a uma dimensão central dos discursos políticos e educacionais contemporâneos.

Com isso, este artigo pretende dar continuidade a uma linha de pesquisa que tem procurado sublinhar a relevância da necessidade de complexificar e dar maior rigor teóricoconceptual à discussão acerca da accountability em educação (AFONSO, 2010, 2012). Finalmente, tentando abrir caminho para o desenvolvimento de novas articulações e análises, chamase a atenção para a corrupção na educação cuja complexidade ainda é insuficientemente conhecida e pesquisada, nomeadamente, nas suas relações com as problemáticas da transparência e da accountability.

\section{O recuo ao cientificismo}

Para a elaboração deste trabalho ${ }^{1}$, seguindo algumas das intuições a que Boaventura Santos (2006) já nos habituou, pareceram-nos muito sugestivas e heurísticas as ideias que este autor discute em torno de uma

1- Trabalho financiado por Fundos Nacionais através da FCT - Fundação para a Ciência e a Tecnologia - no âmbito do Projeto PEst-OE/CED/ Ul1661/2014 sociologia das ausências e de uma sociologia das emergências quando se trata de pensar os limites da racionalidade moderna e ocidental e a natureza do conhecimento hegemônico. A sociologia das ausências procura exercitar a crítica à razão indolente (ou indolência da razão) porque esta "impede de perceber que a compreensão do mundo excede em muito a compreensão ocidental do mundo", ao mesmo tempo em que "transforma interesses hegemônicos em conhecimentos verdadeiros" (SANTOS, 2006, p. 88, p. 90). Dito de outro modo, o que é posto em causa nessa afırmação é, fundamentalmente, a constatação de que não são todos os conhecimentos, ainda que importantes, produzidos em diferentes lugares e culturas, que contam como conhecimentos verdadeiros.

Os conhecimentos assumidos como verdadeiros são essencialmente os conhecimentos científicos ocidentais que são impostos por parte dos poderes hegemônicos como os únicos conhecimentos válidos e legítimos. Do nosso ponto de vista, é isto, aliás, que a chamada economia do conhecimento parece reforçar. Quando poderíamos pensar que a própria universidade estaria a deixar de ser apenas o lugar de produção e reprodução do conhecimento científico, passando a ser também um lugar de valorização concreta e ativa de muitas outras formas legítimas de conhecimento, e das múltiplas possibilidades, em aberto, para a criação de novas sinergias cognitivas e emancipatórias, eis-nos de volta a perspectivas que, afınal, não foram ultrapassadas. É a isso que, na esteira de Jürgen Habermas, chamamos de recuo ao cientificismo. Como refere este autor:

O cientificismo significa a fé da ciência em si mesma ou, dito de outra maneira, o convencimento de que já não se pode entender a ciência como uma forma de conhecimento possivel, senão que devemos identificar o conhecimento com a ciência (HABERMAS, 1982, p. 13). 
Paradoxalmente, é no campo da educação superior, onde é expectável discutir com maior profundidade crítica e epistemológica a produção do(s) conhecimento(s), que está a ser mais difícil resistir aos interesses hegemônicos, os quais vão impondo, de um modo cada vez mais explicitamente unidimensional, o que conta como conhecimento verdadeiro, num recuo histórico indisfarçável ao cientificismo.

É também esse cientificismo e tecnicismo que caracterizam muitas das formas de avaliação vigentes: a avaliação do próprio conhecimento, a avaliação dos profissionais, a avaliação das instituições e também a avaliação das próprias políticas públicas. E, por isso mesmo, é também particularmente notória a proliferação de discursos sustentados numa razão indolente que acompanha o acriticismo dominante quando se trata, mais especificamente, de políticas de accountability em educação.

Para além disso, para quem estuda as políticas educacionais desenvolvidas nas últimas décadas, é muito fácil constatar que as epistemologias e teorias da avaliação estão muito mais avançadas que as políticas e práticas dominantes (frequentemente situadas nos antípodas umas das outras). Com efeito, as políticas para a avaliação (e a própria avaliação como política) têm acentuado essa clivagem que só pode ser explicada porque os interesses hegemônicos no campo educacional impõem a suposta objetividade dos números e o critério das supostas evidências, como se todo o conhecimento fosse avaliável, ou fosse redutível ao que é mensurável ou quantificável pelas tecnologias avaliativas disponíveis (AFONSO, 2009).

Para além de muitas outras formas em que se concretiza, essa hegemonia não deixa de ter como expressão um senso comum partilhado por diferentes perspectivas políticoideológicas, as quais aceitam, e contribuem para naturalizar, a supremacia de formas de avaliação estandardizada, sustentadas por uma racionalidade técnica neopositivista que se contrapõe ao reconhecimento da complexidade e da multireferencialidade da avaliação, e que assim impede a valorização alternativa da pluralidade epistemológica e paradigmática inerente a esse campo.

Apesar de, em certas conjunturas históricas, haver indicadores claros da existência de uma congruência entre determinadas visões político-ideológicas e a valorização de determinadas políticas avaliativas, nas últimas décadas, ao contrário, podemos verificar que, em muitas realidades nacionais, a avaliação em educação não tem sido, do ponto de vista político-ideológico, tão fraturante como seria de esperar.

Ainda que por referência a uma realidade e a uma questão muito distintas das que estamos a tratar, lembramo-nos da denúncia de Marcuse quando falava da manifestação na esfera política de uma "marcada unificação ou convergência de contrários”, o que de algum modo se traduzia (já no final dos anos sessenta) no fato de os programas "dos grandes partidos serem cada vez mais difíceis de distinguir, até mesmo no grau de hipocrisia e nos cambiantes dos estereótipos utilizados” (MARCUSE, 2011, p. 44).

A anterior constatação, apesar de ser feita no final dos anos 1960, parece ter alguma convergência com os indicadores de uma mais recente e notória despolitização da política que, aliás, tem sido analisada em trabalhos de diferente natureza. Como referem, por exemplo, Freire; Belchior (2010, p. 109):

Não obstante ter sido provada a importância da ideologia nas democracias modernas, a literatura admite a existência de alterações substanciais nos conteúdos [...] associados à dimensão ideológica tradicional. $\mathrm{Na}$ realidade, as posições políticas de direita e de esquerda surgem hoje, por vezes, entrelaçadas nos programas partidários.

Em diferentes contextos, outros trabalhos de investigação empírica baseados em metodologias extensivas dão igualmente conta de que existe certa desafetação ou despolitização, 
supostamente decorrente, entre outros fatores, de uma tendência para a homogeneização de posicionamentos de diferentes partidos políticos ou para a "fragilização das clivagens ideológicas" (SCHWEISGUTH, 2004, p. 262-263).

Do nosso ponto de vista, é esse mesmo efeito homogeneizador que alimenta o referido senso comum avaliativo e a razão indolente - os quais, não nos parecendo ser fatos meramente conjunturais, traduzem, antes, a manifestação de uma hegemonia de formas de poder e visões do mundo, sobretudo se considerarmos que essa hegemonia pode (também) ser entendida como:

[...] um conjunto de mecanismos unificadores e reguladores que asseguram à vez a divisão do trabalho discursivo e um grau de homogeneização de retóricas, tópicas e doxas transdiscursivas (ANGENOT, 2010, p. 31) ${ }^{2}$.

Para os objetivos deste texto, uma das questões que, no campo da avaliação e da accountability em educação, tem vindo a ganhar crescente centralidade, e que pode ser pensada em conexão com a hegemonia da uniformização ou homogeneização, é justamente a transparência. Segundo ByungChul Han, a sociedade da transparência é uma sociedade uniformizada em que "as ações tornam-se transparentes quando se tornam operacionais, submetendo-se aos processos do cálculo, da direção e do controlo" (HAN, 2014, p. 11-12). Aliás, essas relações fazem sentido quando verificamos que os discursos da transparência coincidem, pelo menos em parte, com os que são convocados para justificar formas de governação pelos números ou formas de decisão política baseadas em supostas evidências (GREK, 2009).

Tendo como referência a realidade escolar norte-americana, vai neste mesmo sentido, por exemplo, a constatação de que:

\footnotetext{
2- Para uma análise que questiona o sentido mais frequente de hegemonia e as suas resistências em diferentes situações históricas, ver, por exemplo, Scott (2013).
}

[...] uma crescente estandardização, quantificação, competição e comparação em larga escala - pedras angulares da accountability neoliberal - têm sido acompanhadas por dispositivos de transparência (JILL; KANIA, 2014, p. 144)³.

\section{Os paradoxos da transparência}

Tal como a accountability, a transparência constitui um conceito que tem provocado um amplo debate. Aliás, os dois conceitos mantêm relações incertas e um não leva necessariamente ao outro, embora ambos "se refiram a um amplo leque de processos, atores e relações de poder" (FOX, 2007, p. 664-665). Neste texto, ainda que de uma forma sucinta, pretendemos incidir na transparência como um dos valores a que devem referenciar-se os diferentes pilares estruturantes de um modelo ou sistema de accountability.

Com efeito, entre as muitas e diferentes interpretações disponíveis, a transparência tem sido justamente discutida como um dos valores ou exigências da própria democratização das sociedades e, em decorrência disso, um dos fatores que é recorrentemente considerado é o papel dos media e das novas tecnologias da informação e comunicação. Mas, como acentua Andrew Barry (2010, p. 34): “a transparência não significa apenas tornar públicas as informações, mas formar um público que esteja interessado em ser informado".

As análises e expectativas a esse propósito vão das mais pessimistas às mais entusiastas. Há mais ou menos duas décadas e meia, Gianni Vattimo (1992), por exemplo, escrevia que os media não iriam contribuir para "uma sociedade mais transparente, mais consciente de si, mais 'iluminada", mas para "uma sociedade mais complexa, até caótica”, com uma "grande explosão e multiplicação de visões do mundo" - e seria nesse "caos' que residiriam as "esperanças de emancipação" (VATTIMO, 1992, p.10-11).

3- Para uma crítica das formas de accountability dominantes na educação não superior, nomeadamente nos EUA, ver também Afonso (2012). 
Os antípodas dessa visão parecem, no entanto, estar mais presentes quando continuam a surgir novas críticas relativas às consequências mais nefastas que resultam da capacidade (não democrática) de manipulação e propaganda que possuem igualmente os media e as diferentes tecnologias da informação e da comunicação. Se é verdade que podem contribuir (e têm contribuído) para uma sociedade mais democraticamente transparente, também forjam e ampliam opiniões, conceções e interesses, estando, não raras vezes, ao serviço da construção de consensos que tendem a suportar essencialmente os poderes políticos dominantes (CHOMSKY, 2013) ${ }^{4}$.

Transpondo para aqui o que Jonathan Fox, a outro propósito, sugere, dir-se-ia que os media e as tecnologias da informação e da comunicação tanto contribuem para uma transparência baça (opaque transparency), como para uma transparência clara (clear transparency), ainda que, mesmo neste último caso, isso não implique senão uma forma suave de accountability (soft accountability). Para este autor, uma forma mais consequente e dura de accountability (hard accountability) teria, necessariamente. de "ir além dos limites da transparência”, podendo implicar sanções e formas de "compensação e/ou remediação" (FOX, 2007, p. 669).

Em qualquer situação, numa sociedade democrática, há expectativas legítimas de que os media não devem ser imunes aos processos e exigências de accountability, até pelo fato de eles próprios exigirem a accountability aos diferentes setores da sociedade, sobretudo quando se assumem como defensores do interesse público, como sublinha Joaquim Fidalgo (2009). No entanto, considerando as mudanças sociais, políticas e econômicas de índole neoliberal, torna-se necessário pensar criticamente como conciliar exigências do interesse público com interesses privados - uma questão que ganha tanto maior relevância quanto sabemos estarem

4- A este propósito, um trabalho que continua a ser muito sugestivo é o de Pierre Bourdieu (1997). em curso processos de desregulação que valorizam a liberdade concorrencial do mercado, que induzem a concentração empresarial e que procuram o máximo de rentabilidade dos produtos mediáticos (FIDALGO, 2009, p. 314-315).

Mas a transparência não tem só a ver com o direito de acesso à informação, mas também com a expectativa de que ela possa ser uma ferramenta para melhorar a eficiência dos governos e, de algum modo, induzir a accountability. No entanto, na prática, a transparência ainda está muito ligada à necessidade de cumprir as obrigações legais e não, necessariamente, procurar a satisfação das necessidades dos cidadãos (CUCCINIELO; NASI, 2014, p. 911).

0 que atualmente se designa de governo digital ou de governo eletrônico (e-government) inscreve-se numa acepção ampla de sociedade da informação e pode ser justificado pela adoção das TIC "com objetivo de melhorar a eficiência, a eficácia, a transparência e a accountability do governo" (WORLD BANK, 2011) 5 . Para César Calderón, por exemplo, este conceito é mais restritivo do que o de governo aberto (open government), porque, no primeiro caso, o uso das tecnologias de informação e comunicação não implica mudança de valores e "não transforma a sociedade, apenas torna mais fácil a vida dos cidadãos”. No segundo caso, o governo aberto implica "falar fundamentalmente de valores, repensar as administrações e os governos e os seus procedimentos e dogmas". Ainda segundo esse mesmo autor, trata-se de: "abandonar as tautologias administrativas e propiciar a democracia deliberativa" onde, entre outras, as “questões da transparência e da prestação de

\footnotetext{
5- Mais especificamente: "E-Government" refers to the use by government agencies of information technologies [...] that have the ability to transform relations with citizens, businesses, and other arms of government. These technologies can serve a variety of different ends: better delivery of government services to citizens, improved interactions with business and industry, citizen empowerment through access to information, or more efficient government management. The resulting benefits can be less corruption, increased transparency, greater convenience, revenue growth, and/or cost reductions (WORLD BANK, 2011, p. 1).
} 
contas devem fazer parte de uma nova agenda política” (CALDERÓN, 2012, p. 33 e p. 98).

Independentemente da relação complexa e contraditória com a comunicação social e os diferentes usos das novas tecnologias da informação e comunicação, a transparência é uma das dimensões a ter em conta, sobretudo quando as políticas atuais a acentuam como um valor essencial ao funcionamento democrático dos governos, das instituições e das organizações de diferente natureza (e, por isso, também dos modelos e sistemas mais democráticos de accountability). Como refere Daniel Innerarity:

A transparência é, sem dúvida, um dos principais valores democráticos, graças ao qual os cidadãos podem controlar a atividade dos eleitos, verificar o respeito pelos procedimentos legais, compreender os processos de decisão e confiar nas instituições políticas (INNERARITY, 2013, p. 94).

Mas a transparência é discutida em muitos outros domínios da vida social e organizacional (da educação à saúde; da cultura à política, da economia às finanças, da administração racional-burocrática à nova gestão pública...). Sendo um defensor desta última, Christopher Hood sublinha que “a tensão entre a procura da transparência e a evitação da culpa está no centro de alguns dos problemas mais comuns da gestão pública” (H00D, 2007, p. 191). Já no que diz respeito aos sistemas econômico e financeiro, por exemplo, os objetivos da transparência democrática têm sido sublinhados como uma condição importante que vai para além do bom funcionamento do próprio capitalismo, quer ao nível nacional, quer ao nível internacional e supranacional. Com efeito, como sublinha a obra mais recente de Thomas Piketty (2014, p. 791):

[...] a transparência económica e financeira não é simplesmente um desafio fiscal. É também, e pode sobretudo ser, um desafio de governança democrática e de participação nas decisões.

A transparência, em certas situações, acaba também por ser utilizada como uma tecnologia da própria accountability na medida em que "o que é contado é o que conta”. E o que é contado esconde muitas vezes importantes dimensões que não interessam ser publicitadas. Esta é uma das razões pelas quais, por vezes, "a transparência faz mais para legitimar a ação política dos que a promovem" do que para atingir outros objetivos (JILL; KANIA, 2014, p. 143), não sendo também por acaso que se pode falar da "opacidade da transparência" (FENSTER, 2006). Aliás, as críticas às eventuais contradições entre os discursos e as práticas fazem com que a transparência seja objeto de uma "reivindicação efusiva" que pode traduzirse numa forma de coação ou violência, sobretudo quando "o imperativo da transparência torna suspeito tudo o que não se submete à visibilidade" (HAN, 2014, p.11 e p. 25).

A esse propósito, há mesmo quem fale de "tirania da transparência" (STRATHERN, 2000). Talvez por isso se verifique uma tendência "a supor automaticamente que algo é verdadeiro quando é transparente, que toda a representação falsifica e que todo o segredo é ilegítimo" (INNERARITY, 2013, p. 93). Nesta mesma linha, Clare Birchall chama a atenção para a necessidade de pensar as relações e tensões que efetivamente existem entre a transparência e a confidencialidade, em vez de cada uma delas continuar a ser pensada como tendo conotações completamente opostas e inconciliáveis. A transparência como ideal político e cultural, escreve a autora, "tem deixado que a confidencialidade acumule conotações negativas" e a transparência seja vista como um valor eminentemente democrático.

Contrariando esta representação social, e seguindo o pensamento de Derrida, a autora escreve que a transparência pode, em certas situações, pôr em causa alguns valores de liberdade e democracia, nomeadamente por 
pressupor alguma "intolerância em relação à singularidade” (BIRCHALL, 2011, p. 12). São esses paradoxos da transparência que António Nóvoa sintetiza bem quando escreve que "vivemos governados por um excesso de estímulos, amplificados por uma sociedade que encontra na permanente exposição a melhor forma de se esconder" (NÓVOA, 2005, p. 10).

Em síntese, todas essas observações ilustram, de uma forma muito sucinta, alguns dos paradoxos da transparência. Ela é, apesar desses múltiplos lados contraditórios, uma dimensão fundamental da democracia, não fazendo qualquer sentido esperar que a transparência seja preocupação, nem mesmo retórica, da agenda dos regimes políticos autoritários e adversos aos mais elementares direitos humanos. Como escreve Joseph Stiglitz (1999, p. 26): "é sob o manto do sigilo que os direitos das pessoas são frequentemente revogados”. Por isso, não é por acaso que os regimes autoritários ou ditatoriais são mais propícios a práticas de corrupção. A esse propósito, a presidente da organização Transparency Internacional, Huguette Labelle, sublinha que "as raízes das práticas de corrupção têm a ver com a falta de transparência e accountability" (LABELLE, 2013, p. xiii). Para falar de transparência, na acepção que aqui interessa sublinhar, implica necessariamente discutir a densidade, a qualidade e os limites da própria democracia, sendo a corrupção, enquanto "veneno da democracia” (ROSANVALLON, 2010, p. 66), um dos seus mais sérios limites.

\section{Accountability, transparência e corrupção em educação}

A corrupção é um fenômeno antigo, muito embora tenha começado a ser objeto de atenção global apenas nos anos 1990 (HEYNEMAN, 2013) ${ }^{6}$.

6- Entretanto, algumas das organizações internacionais que têm contribuído para a "construção internacional de um novo discurso sobre a corrupção" começam elas próprias a estar sob escrutínio, parecendo existir alguma divergência na interpretação do papel que desenvolvem (COEURDRAY, 2004).
Para Peter Bratsis (2003, p. 10), “a ideia de corrupção tornou-se tão universal e tão indiscutivel que as suas causas, especificidades históricas e funções sociais tendem a ficar ocultas". A partir de uma retrospetiva histórica, o autor mostra que "há uma diferença significativa e muito negligenciada na compreensão moderna e pré-moderna de corrupção" (BRATSIS, 2003, p. 10), concluindo que "as categorias de público e de privado fazem parte integrante da moderna noção de corrupção” (BRATSIS, 2003, p. 12).

Frequentemente, são acentuadas as polarizações definindo a corrupção no campo da educação "como o uso sistemático do serviço público para benefício privado, decorrendo daí um impacto significativo para o acesso, a qualidade e a equidade" (HALLAK; POISSON, 2007, p. 17). Arvind Jain é ainda mais enfático quando escreve que "embora seja difícil chegar a acordo sobre uma definição precisa há consenso de que a corrupção se refere a atos nos quais o poder de um cargo público é usado para ganhos pessoais" (JAIN, 2001, p. 73). Trata-se de definições de corrupção que mostram que "o interesse próprio e o interesse público frequentemente conflituam" (ROSE-ACKERMAN, 1999, p. 225).

Todavia, essa tendência para falar de corrupção apenas quando está em causa o interesse público é contestada por outros autores e por outras agências que entendem que a corrupção não deve ser considerada apenas quando diz respeito ao domínio público, mas também ao privado (POESCHL; RIBEIRO, 2010). Para atender a esta crítica, uma definição mais abrangente, e que nos parece ser particularmente interessante do ponto de vista heurístico, pode sintetizar-se na fórmula proposta por Robert Klitgaard: corrupção = monopólio + discricionariedade - accountability. Para o autor, quer se considere uma atividade pública, privada ou sem fins lucrativos, tenderá a haver corrupção quando uma organização ou pessoa tem o poder exclusivo sobre um bem ou um serviço, pode usar de discricionariedade para decidir e não está sujeita a nenhuma forma de accountability (KLITGAARD, 1998). 
Muito embora atravesse todos os setores da vida social, o campo da educação é particularmente vulnerável à corrupção. Mesmo assim, ainda não há muita literatura disponível que seja suficientemente abrangente e sistemática na abordagem dos vários aspectos da corrupção em educação. Há vários tipos de corrupção (política, legislativa, administrativa, burocrática...), mas ainda assim as fronteiras entre corrupção e não corrupção nem sempre são facilmente delimitáveis.

Por vezes, as razões estão muito próximas de uma má gestão dos recursos públicos, outras vezes as razões são mais graves e dolosas, sendo a esse propósito referenciados problemas muitos diversos, como o favoritismo, o clientelismo, o nepotismo, o suborno, entre outros. No que diz respeito à educação, os atos de corrupção podem ocorrer pela compra de diplomas e certificados, adulteração de matrículas, falsificação de classificações, fraude acadêmica, manipulação de concursos, desvio de subsídios, desvios no fornecimento de alimentação e material escolar, desvio de fundos para a investigação, derrapagem nos orçamentos para a construção de edifícios escolares, entre muitos outros casos.

As situações de vulnerabilidade e de desigualdade, quer em relação aos salários dos professores, quer em termos de condições de acesso à educação por parte das classes sociais com menos recursos materiais e simbólicos, são também fatores que predispõem a comportamentos de corrupção relativamente à procura e usufruto da educação escolar. Mas, como observa, Luís de Sousa (2011, p. 153):

[...] a corrupção não se manifesta apenas entre os mais carenciados. Sendo um fenómeno de poder, ela é sobretudo praticada por quem possui os conhecimentos, as influências e os recursos para o fazer (SOUSA, 2011, p. 153).

Em algumas situações, uma parte significativa de investimentos que deveriam ser aplicados na educação, e que muitas vezes resultam de elevados empréstimos de agências internacionais, acabam por ser desviados antes de chegarem aos seus destinatários. A corrupção tem assim enormes consequências educacionais e graves repercussões em termos de desenvolvimento e de agravamento das desigualdades sociais: "acima de tudo, tem causado e continua a causar pobreza endémica" (MORGAD0, 2011, p. 58).

0 impacto global da corrupção é difícil de medir, embora alguns aspectos possam ser quantificados (OSIPIAN, 2007). Mas essa dificuldade ocorre também em aspectos específicos, como acontece, por exemplo, quando se pretende verificar o impacto da corrupção nos resultados escolares (HALLAK; POISSON; 2002). Um estudo relativamente recente, baseado numa amostra de 50 países, mostrou haver uma relação estatisticamente significativa entre níveis elevados de corrupção e baixos resultados escolares (HUANG, 2008).

Alcançando, por vezes, perdas e desvios muito elevados, medidos em relação ao produto interno bruto de um determinado país, os impactos são muitos e diversificados e ocorrem em qualquer nível de ensino e em qualquer nível da administração do sistema educativo. Quer no ensino superior, quer no ensino não superior, existem problemas de corrupção com implicações no desenvolvimento cultural, científico e tecnológico, na construção da cidadania e na promoção dos direitos humanos, sendo sempre indutores de distorções profundas nas expectativas relativas à qualidade da formação humana e profissional. Com efeito:

As instituições de educação superior não são exceção em termos de corrupção, nem são um oásis livre de corrupção. Elas são parte da economia e da sociedade onde a corrupção parece ser normal. Assim, a corrupção que tem lugar nas instituições de educação superior faz parte integrante de uma rede de relações corruptas que dominam a sociedade. [Todavia], fazer uma estimativa 
da corrupção na educação superior é muito mais difícil do que estimar a economia paralela (OSIPIAN, 2007, p. 314).

Acorrupção na educação superior (quetem vindo a constituir uma preocupação crescente em diferentes países, independentemente do seu lugar no sistema mundial) tem aspectos comuns ao que acontece noutras áreas da vida social e noutros níveis do sistema educativo, muito embora apresente também especificidades (RUMYANTSEVA, 2005; PENALVA BUITRAGO, 2010). Algumas dessas especificidades dizem respeito, por exemplo, à maior invisibilidade social e institucional das práticas pedagógicas e de investigação, bem como à opacidade de muitas das decisões administrativas, o que torna mais difícil o escrutínio por parte dos pares e de outros atores. Se há áreas de grande consenso sobre o que constitui corrupção, como é o caso da fraude acadêmica, há também áreas em que a perceção é diferenciada de país para país, não tendo necessariamente uma conotação negativa, como é o caso da utilização de uma percentagem do valor das bolsas de investigação para cobrir despesas administrativas das próprias universidades.

Alguns autores também apontam o fato de haver instituições de educação superior que, ao concederem incentivos monetários para os docentes e pesquisadores publicarem em revistas de maior impacto na comunidade científica, induzem indiretamente práticas de plágio ou mesmo o mau uso e apropriação indevida do trabalho de subordinados (CHAPMAN; LINDNER, 2014). Em síntese, na educação superior, para além de uma multiplicidade de fatores que já são conhecidos ou de que se suspeita, há também novos fatores emergentes a ter em conta. Como refere Marta Shaw, em tempos de capitalismo acadêmico, parece já não ser improvável que a existência de crescentes pressões competitivas possa favorecer condutas antiéticas e corruptas (SHAW, 2013).

A partir da confırmação da existência de corrupção na educação, que começa a ser feita de forma mais sistemática em diferentes relatórios internacionais e estudos empíricos, as estratégias que são propostas para alterar ou mitigar essa realidade são diversas, sendo de salientar, por exemplo, o perfil das lideranças, a defınição e operacionalização de códigos de conduta e o desenvolvimento de modelos ou sistemas de accountability:

Um elemento fundamental numa estrutura organizacional eficaz é um sistema exequivel de accountability que estabeleça claramente as regras e procedimentos associados a diferentes funções dentro da universidade, forneça um mecanismo de monitorização da conformidade e especifique as consequências em caso de incumprimento. [...] as universidades precisam funcionar com suficiente transparência para que os interessados (stakeholders) possam ver que as responsabilidades e os benefícios são distribuídos de forma justa e apropriada (CHAPMAN; LINDNER, 2014, p. 18).

Nenhum país do mundo está imune à corrupção, mas há países que são mais vulneráveis do que outros pelo próprio fato de o funcionamento das instituições não ser indiferente nem à natureza dos regimes políticos, nem à natureza dos próprios sistemas de governo das organizações educativas (universidades, institutos superiores politécnicos ou faculdades) e seus enquadramentos jurídicos.

Como mostram alguns exemplos de regimes não democráticos, as próprias relações entre o Estado e a educação superior podem ser baseadas na corrupção. Neste caso, a autonomia das universidades pode ser uma resposta a esses constrangimentos na medida em que "a autonomia, por si mesma, não erradica a corrupção, mas pode diminui-la consideravelmente" (OSIPIAN, 2008, p. 44). Mas a autonomia nunca é uma panaceia para a resolução de todos os problemas. Nesse sentido, esperar que a autonomia seja um antídoto eficaz contra a corrupção dependerá, entre outros 
fatores, da sua natureza jurídico-normativa, da qualidade democrática que possibilita e da forma como os atores institucionais se apropriam dessa mesma autonomia.

A esse propósito, há na literatura que revimos exemplos paradoxais relativos à autonomia das universidades. Ela tanto pode signifıcar a possibilidade de realização de um ideário congruente com os objetivos de uma sociedade democrática, como pode significar "menos accountability e potencialmente mais oportunidades para práticas antiéticas” (SALMI; HELMS, 2013, p. 109).

Se em relação à autonomia das instituições de ensino superior há diferenças importantes e práticas paradoxais, não deixa de ser muito importante registar os avanços de natureza política verificados em muitos países que tiveram regimes autoritários ou ditatoriais, e que hoje estão em transição ou consolidação democrática, os quais não nos podem fazer esquecer de que há mais ou menos duas décadas, nesses mesmos países, "era ainda um anátema falar de corrupção” (KIMEU, 2014, p. 232).

\section{Para concluir (provisoriamente)}

Uma das obsessões das políticas para a educação nas últimas décadas tem sido a mensuração e quantificação, ao serviço das quais tem estado a avaliação estandardizada que, por sua vez, tem sustentado a comparabilidade de resultados escolares, quer ao nível nacional, quer ao nível internacional. Apesar da sua crescente sofisticação técnico-metodológica, o viés neopositivista de muitas dessas formas de avaliação é congruente com o recuo ao cientificismo, que não reconhece ou não valoriza senão as disciplinas escolares que constituem o core curriculum que os poderes dominantes consideram necessário à competitividade, numa economia do conhecimento que se amplia com a crescente internacionalização do capitalismo.

Os mecanismos de vigilância panóptica a respeito do campo educacional são muitos e variados, frequentemente constituídos pelos resultados de exames externos e por rankings, estando estes, não raras vezes, ao serviço de políticas de accountability que, em alguns sistemas educativos, têm como consequência a culpabilização das escolas e dos professores. Por essas e outras razões, temos defendido a necessidade de pensar outras concepções de accountability que sejam mais justas e democráticas. (AFONSO, 2012).

Assim, dando continuidade a uma linha de pesquisa centrada na problemática da accountability em educação, este artigo pretendeu, ainda que de uma forma breve, sublinhar a complexidade inerente a alguns conceitos associados, como o conceito de transparência, e ao mesmo tempo quis chamar a atenção para o problema da corrupção em educação que, sendo claramente relacionável com a transparência e a accountability, ainda não tem suficiente visibilidade no campo da pesquisa. A esse propósito, aliás, será necessário analisar com maior profundidade as práticas de corrupção em educação que, em muitas situações, são (paradoxalmente) induzidas pela necessidade de dar resposta à governação baseada nos números, nos rankings e nas (supostas) evidências, anulando completamente as expectativas legitimas em torno da transparência dos processos educacionais e das decisões políticas. 


\section{Referências}

AFONSO, Almerindo Janela. Nem tudo o que conta é mensurável ou comparável: crítica à accountability baseada em testes estandardizados e rankings escolares. Revista Lusófona de Educação, Lisboa, v. 13, n. 13, p. 13-29, 2009.

AFONSO, Almerindo Janela. Para uma concetualização alternativa de accountability em educação. Educação \& Sociedade, Campinas, v. 33, n.119, p. 471-484, abr./jun. 2012.

AFONSO, Almerindo Janela. Um olhar sociológico em torno da accountability em educação. In: ESTEBAN, Maria Teresa; AFONSO, Almerindo Janela (Orgs.). Olhares e interfaces: reflexões críticas sobre a avaliação. São Paulo: Cortez, 2010. p. 147-170.

ANGENOT, Marc. El discurso social: los límites históricos de lo pensable y lo decible. Buenos Aires: Siglo XXI, 2010. 226 p.

BARRY, Andrew. Transparency as a political device. In: AKRICH, Madelaine et al. (Orgs.). Débordements: mélange offerts à Michel Callon. Paris: Press de Mines, 2010. p. 21-39. Disponível em: <http://books.openedition.org/pressesmines/721>. Acesso em: 22 nov. 2014.

BIRCHALL, Clare. Introduction to 'secrety and trasnparency': the politics of opacity and openness. Theory, Culture \& Society, v. 28, n. 7-8, p. 7-25, dec. 2011.

BOURDIEU, Pierre. Sobre a televisão. Oeiras: Celta, 1997.115 p.

BRATSIS, Peter. The construction of corruption, or rules of separation and illusions of purity in bourgeois societies. Social Text, Durhan, v. 21, n. 4, p. 9-33, 2003.

CALDERÓN, César. Otro gobierno. Granada: Algón, 2012. 101 p.

CHAPMAN, David W.; LINDNER, Samira. Degrees of integrity: the threat of corruption in higher education. Studies in Higher Education, Oxford, v. 39, n. 10, p. 1-22, jun. 2014.

CHOMSKY, Noam. Mídia: propaganda política e manipulação. São Paulo: WMF: Martins Fontes, 2013. 107 p.

COEURDRAY, Murielle. Le double jeu de l'import-export symbolique: la construction internationale d'un nouveau discours sur la corruption. Actes de la Recherche em Sciences Sociales, Paris, n. 151-152, p. 80-90, 2004.

CUCCINIELLO, Maria; NASI, Greta. Transparency for trust in government: how effective is formal transparency? International Journal of Public Administration, Oxford, v. 37, n. 13, p. 911-921, 2014.

FENSTER, Mark. The opacity of transparency. lowa Law Review, lowa, v. 91, p. 885-949, 2006. Disponivel em: <http://scholarship. law.ufl.edu/cgi/viewcontent.cgi?article=1059\&context=facultypub/>. Acesso em: 4 dez. 2014.

FIDALGO, Joaquim. 0 lugar da ética e da auto-regulação na identidade profissional dos jornalistas. Lisboa: Fundação Calouste Gulbenkian, 2009. 500 p.

FOX, Jonathan. The uncertain relationship between transparency and accountability. Development in Practive, Oxford, v. 17, n. 4-5, p. 663-671, 2007.

FREIRE, André; BELCHIOR, Ana Maria. Os significados de 'esquerda' e de 'direira' para os portugueses. In: VIEGAS, João Manuel Leite; SANTOS, Susana; FARIA, Sérgio (Orgs.). A qualidade da democracia em debate: deliberação, representação e participação políticas em Portugal e Espanha. Lisboa: Mundos Sociais, 2010. p.107-129.

GREK, Sotiria. Governing by numbers: the PISA 'effect' in Europe. Journal of Education Policy, Oxford, v. 24, n. 1, p. 23-37, 2009. HABERMAS, Jürgen. Conocimiento e interés. Madrid: Taurus, 1982. 348p.

HALLAK, Jacques; POISSON, Muriel. Ethics and corruption in education. Paris: Unesco/International Institute for Educational Planning, 2002. Disponivel em: <http://www.unesco.org/iiep/PDF/Forum15.pdf>. Acesso em: dez. 2014. 
HALLAK, Jacques; POISSON, Muriel. Corrupt schools, corrupt universities: what can be done? Paris: Unesco/International Institute for Educational Planning, 2007. http://unesdoc.unesco.org/images/0015/001502/150259e.pdf

HAN, Byung-Chul. A sociedade da transparência. Lisboa: Relógio D’Água, 2014.

HEYNEMAN, Stephen. Higher education institutions: why they matter and why corruption puts them at risk. In: SWEENEY, Gareth; DESPOTA, Krina; LINDNER, Samira (Orgs.). Global corruption report: education, transparency international. Abingdon: Earthscan by Routlege, 2013. p. 101-107.

H00D, Christopher. What happens when transparency meets blame-avoidance? Public Management Review, v. 9, n. 2, p. 191 210, 2007.

HUANG, Francis L. Corruption and educational outcomes: two steps forward, one step back. International Journal of Education Policy \& Leadership, Fairfax, v. 3, n. 9, p. 1-10, 2008. Disponível em: <http://www.ijepl.org >. Acesso em: 22 nov. 2014.

INNERARITY, Daniel. Un mundo de todos y de nadie: piratas, riesgos y redes en el nuevo desorden global. Barcelona: Paidós, 2013. 190 p.

JAIN, Arvind K. Corruption: a review. Journal of Economic Surveys, v. 15, n. 1, p. 71-21, 2001.

JILL, Koyama; BRIAN, Kania. When transparency obscures: the political spectacle of accountability. Journal for Critical Education Policy Studies, v. 12, n. 1, p. 143-169, 2014.

KIMEU, Samuel. Corruption as a challenge to global ethics: the role of Transparency International. Journal of Global Ethics, Oxford, v. 10, n. 2, p. 231-237, 2014.

KLITGAARD, Robert. International cooperation against corruption. Finance \& Development, v. 35, n. 1, p. 3-6, 1998. Disponível em: <https://www.imf.org/external/pubs/ft/fandd/1998/03/pdf/klitgaar.pdf>. Acesso em: 17 dez. 2014.

LABELLE, Huguette. Preface. In: SWEENEY, Gareth; DESPOTA, Krina; LINDNER, Samira (Orgs.). Global corruption report: education, transparency international. Abingdon: Earthscan by Routlege, 2013. p. xiii-xiv.

MARCUSE, Herbert. 0 homem unidimensional. Sobre a ideologia da sociedade industrial avançada. Lisboa: Letra Livre, 2011. 319p.

MORGADO, Maria José. Investigação criminal do nosso descontentamento. In: SOUSA, Luís de; SOARES, Domitília (Orgs.). Transparência, justiça e liberdade: em memória de Saldanha Sanches. Lisboa: RCP, 2011. p. 55-72.

NÓVOA, António. Evidentemente: histórias da educação. Porto: Asa, 2005.127 p.

OSIPIAN, Ararat. L. Corruption in higher education: conceptual approaches and measurement techniques. Research in Comparative and International Education, Oxford, v. 2, n. 4, p. 313-332, 2007.

OSIPIAN, Ararat. L. Corruption and coercion: university autonomy versus State control. European Education, Armonk, v. 40, n. 3, p. $27-48,2008$.

PENALVA BUITRAGO, José. Corrupción en la universidad: el ocaso de educación. El triunfo de la endogamia. Madrid: Ciudadela Libros, 2010. 197 p.

PIKETTY, Thomas. 0 capital no século XXI. Lisboa: Intrínseca, 2014. 910p. (Temas e debates. Círculo de leitores).

POESCHL, Gabrielle; RIBEIRO, Raquel. Ancoragens e variações nas representações sociais da corrupção. Análise Social, Lisboa, v. 45, n. 196, p. 419-445, 2010.

ROSANVALLON, Pierre. La legitimidad democrática: imparcialidad, reflexividad y proximidad. Barcelona: Paidós, 2010. 317 p.

ROSE-ACKERMAN, Susan. Corruption and government: causes, consequences and reform. Cambridge: Cambridge University Press, 1999. $266 \mathrm{p}$. 
RUMYANTSEVA, Nataliya L. Taxonomy of corruption in higher education. Peabody Journal of Education, v. 80, n. 1, p. 81-92, 2005.

SALMI, Jamil; HELMS, Robin M. Governance instruments to combat corrution in higher education. In: SWEENEY, Gareth; DESPOTA, Krina; LINDNER, Samira (Orgs.). Global corruption report: education, transparency international. Abingdon: Earthscan by Routlege, 2013. p. 108-112.

Santos, Boaventura de Sousa. A gramática do tempo. Para uma nova cultura política. Porto: Afrontamento, 2006. 464p.

SCHWEISGUTH, Etienne. Convergência ideológica e declínio do interesse político. In: VIEGAS, João Manuel Leite; PINTO, António Costa; FARIA, Sérgio (Orgs.). Democracia, novos desafios e novos horizontes. Oeiras: Celta, 2004. p. 257-276.

SCOTT, James C. A dominação e a arte da resistência: discursos ocultos. Lisboa: Letra Livre, 2013. 340 p.

SHAW, Marta. Impacts of globalisation on the academic profession: emerging corruption risks in higher education. In: SWEENEY, Gareth; DESPOTA, Krina; LINDNER, Samira (Orgs.). Global corruption report: education, transparency international. Abingdon: Earthscan by Routlege, 2013. p. 194-201.

SOUSA, Luís de. A sociedade civil contra a corrupção. In: SOUSA, Luís de; SOARES, Domitília (Orgs.). Transparência, justiça e liberdade: em memória de Saldanha Sanches. Lisboa: RCP, 2011. p. 147-162.

STRATHERN, Marilyn. The tyrany of transparency. British Educational Research Journal, London, v. 26, n. 3, p. 309-321, 2000.

STIGLITZ, Joseph. On liberty, the right to know, and public discourse: the role of transparency in public life. Oxford, 1999. Disponível em: <https://www0.gsb.columbia.edu/faculty/jstiglitz/download/2001_On_Liberty_the_Right_to_Know_and_Public.pdf >. Acesso em: 15 dez. 2014.

SWEENEY, Gareth; DESPOTA, Krina; LINDNER, Samira (Orgs.). Global corruption report: education, transparency international. Abingdon: Earthscan by Routlege, 2013. 418 p.

VATTIMO, Gianni. A sociedade transparente. Lisboa: Relógio D’Água, 1992, 87 p.

WORLD BANK. E-Government, 2011. Disponível em: <http://web.worldbank.org/WBSITE/EXTERNAL/TOPICS/ EXTINFORMATIONANDCOMMUNICATIONANDTECHNOLOGIES/EXTEGOVERNMENT/0,,contentMDK:20507153 menuPK:702592 pagePK:148956 piPK:216618 theSitePK:702586,00.html>. Acesso em: 16 dez. 2014.

Recebido em: 29.01.2015.

Aprovado em: 25.03.2015.

Almerindo Janela Afonso é sociólogo, doutor em educação, diretor do Departamento de Ciências Sociais da Educação, do Instituto de Educação, da Universidade do Minho (Portugal). É também presidente da Sociedade Portuguesa de Ciências da Educação e membro do Conselho Nacional de Educação. 